\title{
60 años de la UNAM en San Antonio
}

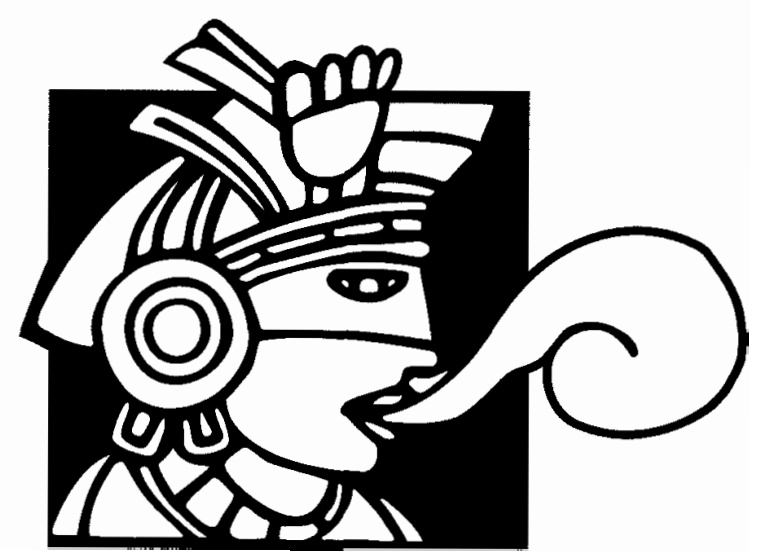




\section{0 años de la UNAM en San Antonio}

Mario Melgar Adalid*

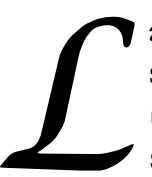

a Escuela Permanente de Extensión de la UNAM en San Antonio (EPESA) se fundó en 1944, hace sesenta años, lo que ahora celebramos. Ocurrió a iniciativa de un grupo de personalidades de la ciudad de San Antonio, ligados a México y conocedores del papel de la UNAM en nuestro país. Algunos de ellos habían participado o conocían los programas iniciados por el Rector José Vasconcelos en los años veinte para acercar a la comunidad mexicana residente en Estados Unidos y a los ciudadanos estadunidenses interesados en nuestra lengua y cultura. Como es sabido fue el maestro Vasconcelos quien fundó la Escuela de Verano, actualmente el moderno Centro de Enseñanza para Extranjeros (CEPE) y él tuvo una cercanía anímica con esta región de Texas, en virtud de su estancia juve-

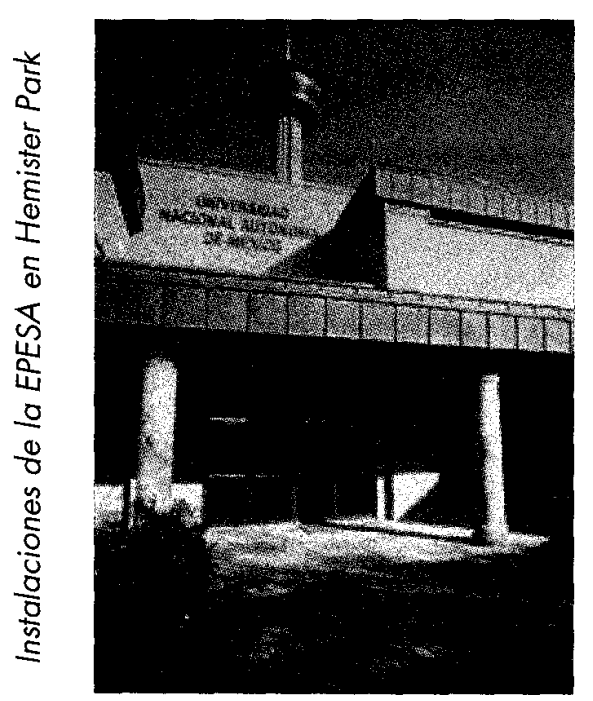

nil en Laredo y de sus frecuentes viajes a San Antonio.

Con estos antecedentes se inauguraron los "Cursos Temporales de Extensión Universitaria", denominados como "Los Cursos"que fueron impartidos por personal académico de la UNAM, originalmente para un público de habla española, que después interesaron a personas de habla inglesa, por lo que se amplió la oferta de los cursos de español. Es interesante que estos cursos iniciaron cuando el mundo vivía los difíciles momentos de la II Guerra Mundial. Estos programas de extensión universitaria tuvieron un éxito inmediato y fueron generando la necesidad de su ampliación. Entre 1944 y 1972 se impartieron en instituciones académicas como Brackenridge High School, San Antonio College y Trinity University, entre otras. Congregaron a un número creciente de estudiantes interesados en aprender español, historia y literatura mexicana, así como otras expresiones de nuestra cultura y arte.

Los cursos antes aludidos dieron como consecuencia la creación de la Escuela Permanente que fue fundada en 1972. A invitación del Ayuntamiento de la Ciudad de San Antonio y con el patrocinio de El Patronato de la Cultura Hispanoamericana, la UNAM comenzó a ofrecer cursos todo el año. Las instalaciones originales que fueron un pabellón de la feria de 1968 ya desaparecieron. El edificio que actualmente alberga las instalaciones de la EPESA fue construido por la Ciudad de San Antonio específicamente para la UNAM

*Director de la Escuela Permanente de Extensión de la UNAM en San Antonio (EPESA). 
y se inauguró en 1987 por el entonces Rector Jorge Carpizo.

Las instalaciones se encuentran en el llamado Parque de la Hemisferia, utilizado para la feria mundial que tuvo verificativo en el año de 1968. Se trata de un espacio especialmente diseñado para impartir cursos, con las condiciones necesarias para disponer y disfrutar de un lugar amplio, moderno, con salones adecuados e iluminados, con un buen auditorio y una explanada propia para exposiciones artísticas.

La EPESA ha tenido un crecimiento singular y sostenido desde su creación. La UNAM ha dotado a la EPESA de condiciones muy favorables para la enseñanza del español para extranjeros, la enseñanza de inglés como segunda lengua y para la oferta y desarrollo de diversos programas de extensión cultural. En este sentido se destaca la red de cómputo que liga a la EPESA con las dependencias universitarias a través de la fibra óptica y más recientemente con la operación del sistema de Internet II. La EPESA cuenta además con un moderno laboratorio de idiomas. El Laboratorio Ingeniero Gilberto Borja Navarrete recientemente inaugurado, está dotado con el mejor equipo técnico existente en el mercado y cuenta con apoyo de sistemas de cómputo que facilitan el aprendizaje de lenguas.

La EPESA forma parte de la red de instituciones del Centro de Enseñanza para Extranjeros (CEPE). Sirvió como modelo para la creación de la Escuela de Extensión en Canadá (ESECA) en 1995 y para la Escuela de Extensión de la UNAM en Chicago, (ESECH) en 2002.

Su labor sustantiva consiste en enseñar español para extranjeros y el idioma inglés como segunda lengua. De esta manera, prepara es- tudiantes mexicanos y de otras nacionalidades, cuya primera lengua es distinta al inglés, para sus estudios en programas de universidades de Estados Unidos. Asimismo, imparte español y materias relacionadas con la cultura de México a las personas interesadas en nuestra lengua y ofrece programas de español para propósitos específicos a organizaciones públicas y privadas del sur de Texas para sus empleados y ejecutivos.

Dada la creciente afluencia de mexicanos a Estados Unidos y el incremento de la relación comercial, turística y cultural entre los dos países, la necesidad del inglés se hizo evidente. La EPESA comenzó su programa de enseñanza del inglés como segunda lengua en 1983. La enseñanza del inglés permite a los estudiantes mexicanos tener un mejor desempeño académico y además integrarse mejor capacitados a la fuerza laboral tanto en México como en Estados Unidos.

También se han impartido cursos de español e inglés fuera de San Antonio. Baste citar los ejemplos de los cursos por videoconferencia y los cursos presenciales de español a profesores del Distrito Escolar 1 de Chicago y a empleados del Ayuntamiento de El Paso, así como los cursos de inglés de sobrevivencia a trabajadores mexicanos en la ciudad de Austin, Texas.

La EPESA brinda apoyo a investigadores y profesores universitarios en estancias cortas y proyectos específicos en Estados Unidos. Desarrolla además un programa de difusión cultural apoyado en las áreas correspondientes de la Coordinación de Difusión Cultural y sirve de enlace entre dependencias universitarias y organizaciones académicas de Estados Unidos a través del sistema de videoconferencia. En cierto sentido puede afirmarse que la EPESA realiza una tarea de embajada 
o representación académica de la UNAM en Estados Unidos al servir como vínculo entre organizaciones educativas y académicas.

La EPESA se encuentra localizada en el Parque de la Hemisferia en el centro de la ciudad de San Antonio. Se ubica a un costado de la llamada Plaza México y contigua a las instalaciones del Instituto de México, organismo de la Secretaría de Relaciones Exteriores que tiene a su cargo la promoción cultural del gobierno federal. Las instalaciones son propiedad de la ciudad de San Antonio y la EPESA tiene celebrado un convenio para disponer de las instalaciones a cambio de becas para aprender español que se ofrecen a trabajadores de la ciudad.

La labor sustantiva de la EPESA se sustenta en el apoyo académico, administrativo y logístico que recibe del CEPE, en la solidez de su personal académico, y en la interacción de los profesores de la EPESA con sus colegas de oras instituciones que realizan una labor similar en la enseñanza de lenguas. En este sentido se han vuelto tradicionales los encuentros de profesores de español o de inglés como segunda lengua que anualmente se reúnen en las instalaciones de la EPESA para intercambiar experiencias y recibir información de expertos en la materia. La EPESA desarrolla además de sus acciones ordinarias, un programa per- manente de actividades culturales y exposiciones. De igual manera, organiza conferencias, congresos, mesas redondas y simposia sobre cuestiones que atañen a la relación México-Estados Unidos o sobre temas específicos de México de interés para el público de Estados Unidos. Entre las actividades sobresalientes se encuentra la visita de la Orquesta Filarmónica de la UNAM en 1994, para conmemorar el 50 aniversario de la EPESA o reuniones como la del año 2003 "México 2003, Elecciones Intermedias" presidida por el rector de la UNAM Dr. Juan Ramón de la Fuente que congregó a un número importante de asistentes y que contó con la participación de académicos, destacados politólogos y representantes populares.

La EPESA está reconocida como la mejor escuela de enseñanza de español en la región, así como uno de los mejores planteles para la enseñaza del idioma inglés como segunda lengua. En diversas ocasiones ha recibido expresiones públicas y formales de reconocimiento por su labor tanto por parte de las autoridades municipales como de las universidades de la ciudad.

El rector de la UNAM, Dr. Juan Ramón de la Fuente ha visitado la EPESA en cinco ocasiones durante el lapso comprendido entre el año 2000 y el 2004. Anteriormente lo hicie- 
ron en varias ocasiones los rectores Jorge Carpizo y José Sarukhán. Históricamente una pléyade de intelectuales y académicos han participado en actividades de la EPESA. De manera enunciativa se consignan los nombres de escritores como Elena Poniatowska, Carlos Fuentes, Carlos Monsivaís, Gonzalo Celorio, Hernán Lara, Ángeles Mastreta, Fernando Curiel, Maria Luisa Puga, Felipe Garrido, Vicente Quirarte, Germán Dehesa, Laura Esquivel, Augusto Monterroso, Andrés Henestrosa, José Agustín, Tita Valencia e Ignacio Solares. También han participado en actividades de la EPESA académicos de la talla de Beatriz de la Fuente, Manuel Toussaint, Julio Jiménez Rueda, Francisco de la Maza, Miguel León-Portilla, María del Carmen Millán, Arturo Arnaiz y Freg, Margo Glantz, José Moreno de Alba, Sergio Fernández, Antonio Castro Leal, Héctor Azar, Justino Fernández, Francisco Monterde, José Moreno de Alba, Carlos Graef Fernández, Guillermo F. Margadant, Arnaldo Córdova, Elisa Vargas Lugo, Teresa Uriarte, Teresa del Conde, Elisa García Barragán.

El objetivo fundamental de la escuela ha sido, desde su fundación, contribuir a un mejor entendimiento entre México y Estados Unidos a través de la enseñanza del inglés y del español, así como mediante la organización de actividades académicas y culturales que promuevan el conocimiento de lo que es México en todas sus facetas.

Un programa innovador es la Certificación del Dominio de la Lengua Española (CEDIE), que permite otorgar a las personas físicas $y$ organizaciones empresariales o académicas que soliciten dicho certificado a partir de un examen de dominio de la lengua española diseñado con base en la experiencia acumulada durante varios lustros en la enseñanza del español a extranjeros.
En 1995 la EPESA obtuvo, por concurso, un contrato con la ciudad de San Antonio para la evaluación de la proficiencia oral en español a sus empleados Este examen se ha aplicado asimismo a diversas organizaciones que lo han solicitado y a la fecha se ha evaluado a alrededor de 3,500 personas

A partir del año 2001, la UNAM celebró con la Secretaría de Relaciones Exteriores unas Bases de Colaboración con el objeto de coordinar esfuerzos tendientes, entre otras importantes cuestiones, a la atención de migrantes mexicanos que viven en Estados Unidos. De esta manera se plantearon algunas líneas de acción de apoyo a migrantes mexicanos. Una de las que han tenido mayor aceptación y éxito es el denominado "inglés de sobrevivencia" que consiste en cursos básicos de inglés a personas que desconocen la lengua y que por razones laborales requieren del inglés para tener un mejor desempeño en sus trabajos en Estados Unidos. Este curso es gratuito y es financiado por empresas estadounidenses que contribuyen de esa manera al mejor desempeño social de los mexicanos en Estados Unidos.

La EPESA ha iniciado un programa de $\mathrm{Ba}$ chillerato Abierto y de conclusión de los estudios cursados en el sistema de la Escuela Nacional Preparatoria. A través de la comunicación vía Internet II se pone en contacto a los alumnos que dejaron truncados sus estudios y se les anima y auxilia para que los concluyan.

La EPESA forma parte de la red de escuelas del Centro de Enseñanza para Extranjeros (CEPE). Como cabeza académica el CEPE le brinda a ésta un invaluable apoyo en sus tareas sustantivas. Uno fundamental es la comisión de profesores de español a la EPESA. Recientemente el CEPE impartió por video- 


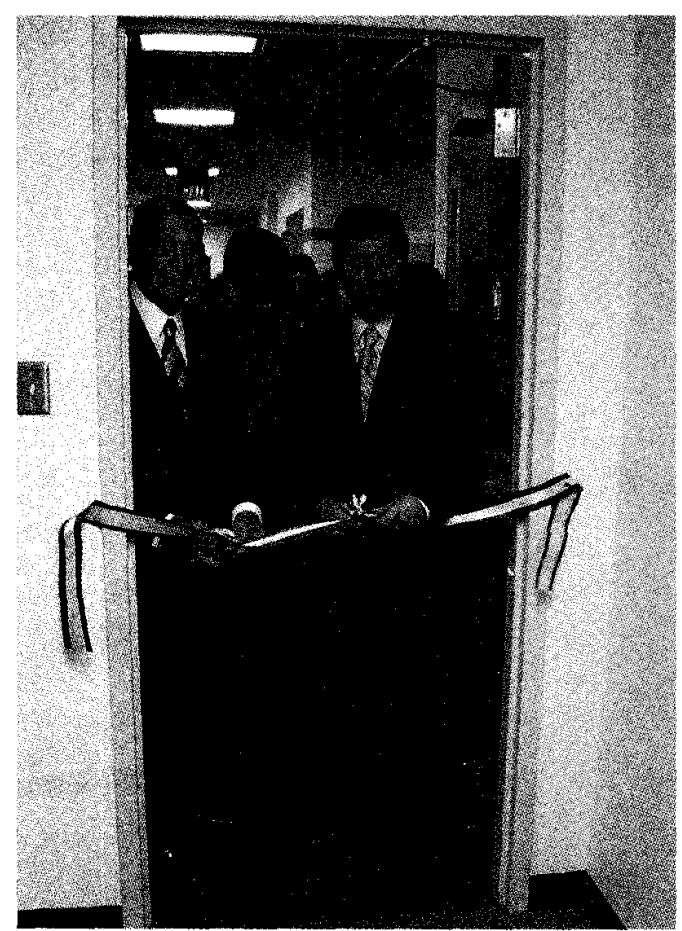

Gilberto Boria Navarrete y el Rector, Juan Ramón de la Fuente

conferencia módulos del Diplomado en Estudios Mexicanos, que atrajeron la atención de un grupo de personas interesadas en profundizar en estas materias en la ciudad de San Antonio. Por otra parte, la EPESA publica en coedición con Editorial Santillana la serie Estoy Listo. Este texto preparado por profesores de la EPESA a lo largo de varios años ha servido a varias generaciones de estudiantes de español en Estados Unidos y Canadá.

Para la celebración de los sesenta años de la EPES $A$ en San Antonio, el CEPE ha preparado junto con la Escuela una serie de actividades académicas y sociales entre las que destacan la visita del Sr. Rector de la UNAM, Dr. Juan Ramón de la Fuente acompañado del Embajador de Estados Unidos en México, Sr. Antonio Garza; la conferencia que el Dr. de la Fuente impartirá en ocasión de recibir el "Pre- sidential Award", galardón otorgado por el Centro de Ciencias de la Salud de la Universidad de Texas (University of Texas Health Science Center); la mesa redonda denominada "Porque estamos aquí", en la que participarán destacados intelectuales mexicanos y estadounidenses para tratar el tema de la migración de mexicanos a Estados Unidos y que será conducida por el Dr. Rector Juan Ramón de la Fuente; la reunión académica "Semántica de las Identidades" en la que participarán los doctores José Moreno de Alba, Vicente Quirarte, Arturo Madrid, Harriet Romo y Francisco Marcos Marín conducida por el Dr. Mario Melgar Adalid, Director de la EPESA y en la que se discutirá la significación de las diversas denominaciones que identifican a los mexicanos y a los latinoamericanos en Estados Unidos, a saber, en otros términos: hispano, latino, méxico-americano, chicano, mexicano, tejano, californio.

La EPESA acuñó una medalla conmemorativa de los sesenta años de trabajo en Estados Unidos. Por una parte la celebración será ocasión propicia para confirmar el acierto de quienes iniciaron este proyecto, y por la otra, para rendir merecido homenaje a quienes lo hicieron posible con su trabajo comprometido y entusiasta.

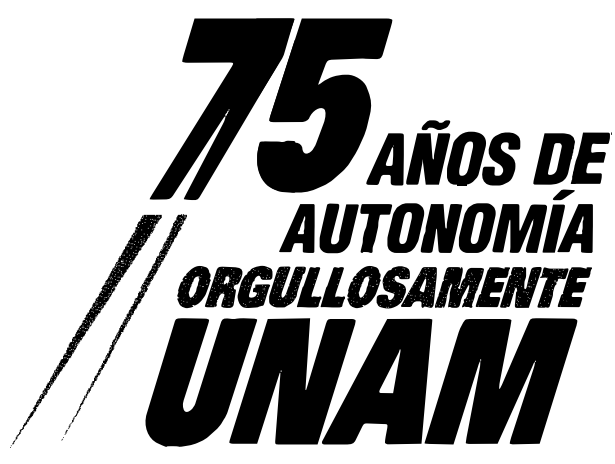

